\title{
Análise da Evasão de Alunos na Licenciatura em Computação
}

\author{
Viviane Vasconcelos ${ }^{1}$, Ermeson Andrade ${ }^{1}$ \\ ${ }^{1}$ Departamento de Informática e Estatística (DEINFO) \\ Universidade Federal Rural de Pernambuco(UFRPE) \\ Pernambuco, Recife, 50670-901 \\ \{viviane.vilela, ermeson.andrade\}@ufrpe.br
}

\begin{abstract}
The lack of a proper background in logic and mathematics by students in Computing Licenciate and the volume of new ideas required of them in the first semesters of the course appear as the main reasons behind the high dropout rates. However, studies conducted rarely propose solutions. Through questionnaires given to teachers and students in the course, the current paper collects data about the perceptions of both groups at the Universidade Federal Rural de Pernambuco, and identifies a few problems that can be solved as a way to lower the dropout rates. Solutions are offered, and can be used in other institutions that face the same dropout problem.
\end{abstract}

Resumo. A falta de embasamento lógico-matemático dos alunos de Licenciatura em Computação e o volume de ideias novas requeridas nos primeiros semestres do curso aparecem como motivos principais da alta taxa de evasão. No entanto, os estudos realizados raramente sugerem soluções para o problema. Através de questionários aplicados a professores e alunos do curso, o presente trabalho levanta dados sobre as percepções de ambos grupos integrantes do curso na Universidade Federal Rural de Pernambuco, e identifica alguns problemas que podem ser corrigidos como forma de diminuir a alta taxa de evasão do curso. Soluções são oferecidas, e podem ser utilizadas em outras instituições que também enfrentam o problema da alta taxa de evasão.

\section{Introdução}

O avanço e disseminação das tecnologias tem criado e facilitado oportunidades em todos os contextos em que estão inseridas. Cada vez mais o mercado de trabalho exige profissionais aptos a lidarem com as tecnologias em todas as áreas de atuação. Cursos superiores voltados à tecnologia vêm crescendo, e junto com essa ocorrência, tem aumentado a necessidade de formar profissionais aptos a ensinar Computação. Isso tem feito com que várias universidades de todo o país incluam em seus catálogos o curso de Licenciatura em Computação(LC). Como outras Licenciaturas, o curso de LC é regido pela Lei de Diretrizes e Bases, que determina a formação de professores da Educação Básica através da graduação em Licenciatura Plena, e a oferta da Licenciatura em Computação vem aumentando gradativamente, à medida que surgem novas possibilidades no Ensino da Computação.

No entanto, existe uma alta taxa de evasão nos cursos de LC. Gomes, Henriques e Mendes (2008) ressaltam a disparidade entre os métodos de ensino utilizados por grande parte dos professores e os estilos de aprendizado diversificados dos alunos. Similarmente, os métodos de estudo dos alunos também precisam ser modificados, uma vez 
que os alunos geralmente estão acostumados a memorizar conceitos e fórmulas, o que não é eficiente no aprendizado da programação. O alto nível de abstração requerido dos alunos em disciplinas introdutórias, como na Introdução à Computação, e uma falta de preparo lógico-matemático por parte dos alunos ingressantes no curso também aparecem como fatores relevantes para a alta taxa de evasão.[Gomes et al. 2008] Júnior e Rapkiewicz (2004) mostram que pesquisas realizadas na área apontam uma preocupação em listar e entender as razões que expliquem porque as disciplinas introdutórias de cursos de Computação possuem as mais altas taxas de reprovação quando comparadas a outros cursos da área de Exatas, no entanto poucas soluções são oferecidas.

$\mathrm{Na}$ Universidade Federal Rural de Pernambuco (UFRPE), embora a oferta de vagas para o curso de LC seja 40 por semestre letivo, esse número começa a cair já a partir do primeiro semestre. À medida que os semestres progridem, é comum ver disciplinas com somente um ou dois alunos matriculados, porque muitos alunos reprovam cadeiras que prendem outras disciplinas na matriz curricular, ou perdem o interesse no curso devido a essas dificuldades iniciais. Com isso em mente, e levando em conta a facilidade de acesso aos alunos e professores do curso de LC na UFRPE, o presente estudo foi executado, para levantar dados sobre possíveis razões para a alta taxa de evasão no curso, e assim propor algumas possíveis soluções que podem ser estendidas a outros cursos de LC em outras universidades do país.

O artigo está organizado da seguinte forma: a seção 2 apresenta o embasamento teórico para o estudo; a seção 3 constitui-se de uma revisão da literatura relacionada; a seção 4 aborda a metodologia utilizada no estudo, enquanto que a seção 5 apresenta os resultados e discussões, assim como propostas de solução. Por fim, a seção 6 apresenta conclusões a serem implementadas não só na UFRPE como em outras instituições de ensino.

\section{Fundamentos}

O curso de LC Na UFRPE tem como objetivo formar professores aptos a abordarem os conteúdos da ciência da computação no ensino Fundamental, Médio e Técnico. São ofertadas 40 vagas por semestre, e o ingresso ocorre através do Exame Nacional do Ensino Médio (ENEM). A matriz curricular está organizada em nove períodos noturnos cujo conteúdo contempla disciplinas obrigatórias na área de Computação assim como disciplinas de Educação, como Fundamentos da Educação, Didática, e Psicologias I e II. No primeiro período, os alunos precisam cursar as seguintes disciplinas obrigatórias: Introdução à Programação, Matemática Discreta, Elementos de Informática, Psicologia I, Fundamentos Filosóficos, Históricos, e Sociológicos da Educação. No segundo período, as disciplinas obrigatórias são: Algoritmos e Estruturas de Dados, Cálculo A I, Introdução à Teoria da Computação, Prática de Ensino de Algoritmos, e Psicologia II. Existe o pareamento entre a base teórica específica na área estudada com uma disciplina de Prática de Ensino, que, no entanto, não são oferecidas pelo Departamento de Educação, mas por professores do próprio departamento em que a LC se encontra inserida.

De acordo com especificações do Departamento de Estatística e Informática (DEINFO) da UFRPE, o curso de LC forma profissionais habilitados ao ensino da Computação no Ensino Fundamental, Médio e Técnico. Algumas das habilidades pretendidas são: 
- Desenvolver atividades de pesquisa e docência em computação e educação;

- Conduzir investigações e contribuir para o desenvolvimento do conhecimento na área de computação de maneira multi, inter, e transdisciplinar;

- Analisar problemas educacionais;

- Atuar no planejamento e execução de currículos e programas de capacitação profissional, em organizações diversas, e em especial aquelas relacionadas a métodos, processos e técnicas da Computação;

- Projetar e implementar ferramentas e soluções computacionais de apoio aos processos de ensino-aprendizagem e de administração escolar para atender as demandas das escolas e instituições de ensino;

- Contribuir para a geração de inovações nos processos de ensino e aprendizagem de maneira a atender as demandas de formação de educadores comprometidos com a transformação social e tecnológica.

Os alunos ingressantes em LC têm experiências diversificadas nas disciplinas introdutórias da computação: enquanto alguns apresentam facilidade no aprendizado e compreensão dos conteúdos, outros enfrentam muitas dificuldades nessas disciplinas[Ambrósio et al. 2011]. Dos Santos e Costa (2006) ressaltam que as disciplinas de Programação e Algoritmos constituem a base para a Ciência da Computação, e seus conteúdos contemplam o ensino de linguagens de programação assim como os conceitos, princípios, e modelos de programação; a programação em si consiste na aplicação direta da resolução de problemas. Nesse sentido, as linguagens de programação tornam-se ferramentas para a concretização da resolução de um problema, que resulta no software em si[dos Santos and Costa 2006].

Nota-se que as disciplinas introdutórias do primeiro e segundo período do curso requerem dos alunos um embasamento teórico superior ao conhecimento dos alunos ingressantes. Devido à extensão dos tópicos introduzidos nas disciplinas de Introdução à Programação, Matemática Discreta, e Algoritmos e Estruturas de Dados, a maioria dos alunos ingressantes precisa cursar as disciplinas mais de uma vez para conseguirem absorver os conteúdos e atingirem notas satisfatórias. As reprovações ocasionam na desmotivação dos alunos ingressantes, assim como uma desconfiança por parte da comunidade acadêmica, o que pode diminuir o número de alunos interessados nos cursos de LC [SILVA et al. 2009]. Considerando que a maioria dos alunos ingressantes no curso de Licenciatura em Computação não conhece uma linguagem de programação antes de iniciarem o curso, talvez seria mais importante construir uma base sólida nesses alunos novatos do que almejar que eles adquiram as habilidades em dois semestres.

\section{Trabalhos Relacionados}

Prietz e Pazeto (2009) apresentam um estudo de caso aplicado ao curso de Licenciatura Plena em Informática na Universidade Federal do Mato Grosso. Dados sobre o ensino, atividades de pesquisa e extensão são apresentados de modo a caracterizarem o curso e a análise quantitativa referente às experiências dos alunos. As autoras ressaltam que Programação I é a disciplina com menor índice de aprovação, e que a média de alunos formados no curso é de onze alunos [Prietch and Pazeto 2009].

Gomes, Henriques e Mendes (2008) destacam que os elevados níveis de insucesso em disciplinas onde são ensinados os conceitos mais básicos de programação, em qualquer grau e sistema de ensino, é um problema universal que tem sido alvo de variadas 
pesquisas, resultando também em diversificados sistemas, sem que contudo o panorama tenha melhorado significativamente. Existe um conjunto de razões que estão na origem do problema, nomeadamente, métodos de ensino e aprendizagem desadequados, falta de vários tipos de competências por parte dos alunos, em particular no que respeita à resolução de problemas, a difícil natureza do tema e uma forte conotação negativa que lhe está associada. As metodologias tradicionalmente utilizadas para aprender/ensinar estes assuntos não são suficientes [Gomes et al. 2008].

Em contrapartida, Ambrósio et. al (2011) descrevem tais dificuldades tomando o discurso de professores e alunos, contrastando os alunos com bom e fraco rendimento. Neste sentido, após um levantamento da literatura internacional na área, os autores descrevem as percepções de professores e alunos sobre as exigências cognitivas e acadêmicas da aprendizagem de programação. Os resultados obtidos sugerem que os fracos alunos apresentam claras dificuldades na abstração dos problemas e tendem para uma resolução por tentativa e erro dos problemas. Os bons alunos descrevem uma maior concentração dos seus esforços na análise aprofundada do problema, sua partição e representação mental, avançando para a resolução com maior clareza cognitiva, organizando a solução em passos sequenciais[Ambrósio et al. 2011].

França et. al (2015) discutem que atualmente é requerido dos estudantes desenvolver diversas habilidades, dentre elas o pensamento computacional. Contudo, no Brasil o ensino de tal habilidade não integra o currículo escolar. Nesse sentido, este artigo discute desafios ao ensino do pensamento computacional na educação básica brasileira, apresentando oportunidades de pesquisa na área. Além disso, é apresentada uma proposta para minimizar alguns dos problemas apontados, a qual demonstrou contribuir com a aprendizagem de estudantes do nível médio durante um curso de desenvolvimento de jogos digitais[França and Tedesco 2015].

Prietz e Pazeto (2010) listam vários fatores que podem gerar a evasão no curso de Licenciatura Plena em Informática na Universidade Federal do Mato Grosso. Dentre os motivos estão a distorção por parte dos alunos das habilidades necessárias para o sucesso no curso, embora informações sobre o curso estejam disponíveis no campus. Fatores socioeconômicos também limitam o turno em que os alunos podem dedicar a um curso superior, uma vez que eles precisam trabalhar para auxiliar no sustento das famílias. [Prietch and Pazeto 2010]

O presente estudo tenta definir as principais dificuldades enfrentadas por alunos novatos do curso de Licenciatura em Computação na Universidade Federal Rural de Pernambuco. Embora algumas razões citadas nos artigos acima são observadas no local do estudo, o foco desse trabalho é nos relatos das experiências dos próprios alunos e professores de LC na UFRPE, para que as alternativas sugeridas para o ensino dos conceitos básicos de Computação abordados nas disciplinas introdutórias do primeiro e segundo períodos do curso sejam relevantes.

\section{Metodologia}

Júnior e Rapkiewicz (2004) pontuam o envolvimento dos alunos e dos professores como grupos distintos e responsáveis pela origem dos problemas no ensino-aprendizagem dos fundamentos de programação[Júnior and Rapkiewicz 2004]. Com isso em mente, para esse estudo foram conduzidas duas pesquisas utilizando a ferramenta Google Forms, onde 
professores e alunos de LC na UFRPE compartilharam dados e opiniões sobre o curso.

Os alunos e professores de LC da UFRPE foram escolhidos para participarem da pesquisa devido à facilidade de acesso aos mesmos por meio de interações diárias. Os formulários foram disponibilizados através das mídias sociais, assim como através da lista interna para alunos e professores da área, e ficaram disponíveis por duas semanas durante o primeiro semestre letivo de 2017. Com os resultados obtidos nas duas pesquisas, um estudo quantitativo foi executado para saber o número de alunos que precisaram cursar as disciplinas de Matemática Discreta, Introdução à Programação e Algoritmos e Estruturas de Dados mais de uma vez. Similarmente, um estudo qualitativo foi realizado para descobrir as opiniões dos alunos com relação a suas experiências com os métodos de ensino adotados pelos professores de LC, assim como a opinião dos professores com relação às possíveis razões para o alto número de reprovações e evasão do curso.

\section{Resultados e Discussões}

Após o fechamento dos questionários, os resultados foram armazenados e foi realizada uma análise das respostas. As respostas abertas foram resumidas levando em consideração a uniformidade de seus relatos.

\subsection{Questionário dos Alunos}

Os trinta alunos que responderam ao questionário indicaram ter ingressado no curso de LC entre os semestres 2012.1 e 2017.1, sendo os quatro que cursam atualmente o primeiro período redirecionados para algumas seções específicas do questionário, visto que suas experiências no curso ainda não contemplam a disciplina de Algoritmos e Estruturas de Dados. As perguntas iniciais pediram que os alunos classificassem suas experiências com programação e conhecimentos lógico-matemáticos antes de iniciar o curso. Os resultados aparecem nas tabelas abaixo.

Tabela 1. Experiência prévia em Programação.

\begin{tabular}{|c|c|}
\hline \multicolumn{2}{|c|}{ Experiência em Programação } \\
\hline Ótima & $15.4 \%$ \\
\hline Regular & $26.9 \%$ \\
\hline Ruim & $19.2 \%$ \\
\hline Péssima & $3.8 \%$ \\
\hline Inexistente & $34.6 \%$ \\
\hline
\end{tabular}

Tabela 2. Conhecimentos Lógico-Matemáticos prévios.

\begin{tabular}{|c|c|}
\hline \multicolumn{2}{|c|}{ Conhecimento Lógico-Matemático } \\
\hline Ótimo & $19.2 \%$ \\
\hline Regular & $65.4 \%$ \\
\hline Ruim & $7.7 \%$ \\
\hline Péssimo & $7.7 \%$ \\
\hline
\end{tabular}

Esses resultados indicam que os próprios alunos têm consciência de suas defasagens ao ingressarem no curso de LC. Embora terem sido aprovados para a entrada no 
curso, os alunos não necessariamente contam com o embasamento apropriado para acompanharem a rápida progressão dos conteúdos.

Com relação às disciplinas do primeiro período do curso, $46.2 \%$ dos alunos cursaram Introdução à Programação uma vez, no entanto, $42.2 \%$ precisaram cursar duas vezes. Já em Matemática Discreta, 30.8\% dos alunos cursaram uma vez, enquanto 50\% precisaram cursar duas vezes. Na primeira disciplina citada, o assunto mais compreendido pelos alunos foi Arquivos, e na segunda, Grafos. Na opinião da maioria dos alunos, o ponto forte dos professores do curso de LC é o domínio do assunto, no entanto o ponto fraco concentra-se na dificuldade de passar o assunto aos alunos, principalmente devido ao fato deles não terem uma formação fundada no domínio didático. Vários alunos mencionaram a dificuldade em acompanhar os assuntos devido ao pouco tempo existente para a obtenção dos conhecimentos.

Das respostas à pergunta sobre sugestões de mudanças ao curso, catorze mencionam a grade curricular assim como detalhes da organização das disciplinas. Alguns alunos reiteram a falta de didática dos professores, mencionando especificamente as disciplinas de Introdução à Programação e Matemática Discreta.

Por fim, $73.1 \%$ dos alunos cursando a partir do segundo semestre afirmam já terem considerado desistir do curso, enquanto $50 \%$ dos alunos do primeiro semestre também já consideraram essa opção. Esses dados reforçam a correlação entre o alto número de reprovações nas disciplinas introdutórias e a desmotivação dos alunos de LC.

\subsection{Questionário dos Professores}

Dos nove professores que responderam ao questionário, cinco possuem formação acadêmica em Ciência da Computação, um em Sistemas de Informação, e os outros não informaram. Com relação à percepção dos conhecimentos lógico-matemáticos dos alunos, seis professores os consideram fracos ou médios, enquanto dois não consideram ter dados suficientes para opinar. No entanto, sete professores consideram os conhecimentos de programação dos alunos como fracos.

Seis professores indicaram utilizar métodos de ensino tradicionais, como aulas expositivas, e apenas dois mencionaram métodos mais contemporâneos, como o ProjectBased Learning (PBL) [Thomas 2000] e o uso de jogos. Todos os professores que responderam ao questionário listam a prova como o método de avaliação utilizado, ainda que alguns também listam outras formas de verificar o aprendizado, como seminários, apresentações e listas de exercício.

Os professores listam como razões para a alta taxa de evasão no curso o turno e dificuldades por parte dos alunos em se dedicarem aos estudos. Apenas dois professores mencionam as dificuldades e reprovações nas disciplinas iniciais como possível razão. Um professor destaca a falta de acompanhamento pedagógico, e um outro atribui a evasão ao fraco embasamento dos alunos.

Cinco professores sugerem mudanças na matriz curricular e um professor afirma que o corpo docente precisa estar mais bem alinhado à proposta do curso. Um professor também destaca que a matriz curricular de LC está sendo reformulada, a fim de atender as demandas do mercado e dos alunos.

Levando em consideração que uma das habilidades que compõem o perfil do gra- 
duado em LC é a contribuição à criação de inovações no ensino e aprendizagem, nota-se que essa prática não vem sendo modelada aos alunos. A rejeição por parte dos professores em acolherem métodos de ensino não tradicionais pode se dar em decorrência de a maioria deles possuírem graduação e pós-graduação em Ciência da Computação em vez de Licenciatura, onde a obrigatoriedade das disciplinas de educação expõem e enfatizam o uso de metodologias de ensino variadas. Entende-se que os professores não têm como modificar a estrutura das disciplinas que lecionam, mas as formas de ensino podem ser reavaliadas visando o melhor aprendizado por parte dos alunos.

\subsection{Soluções Propostas}

Embora a matriz curricular de LC atualmente esteja em processo de revisão, é importante observar que mudanças estruturais isoladas podem não alterar a alta taxa de evasão do curso. É preciso reavaliar a eficácia de se oferecer disciplinas de Prática de Ensino ao mesmo tempo que o assunto específico está sendo construído por parte dos alunos, pois essa estrutura aumenta as chances dos alunos não possuírem a base necessária para fazer escolhas conscientes sobre os métodos de ensino mais apropriados para um tópico qualquer.

Caberia à coordenação do curso considerar a remoção de disciplinas de Prática de Ensino para abrir espaço na matriz curricular para que disciplinas como Introdução à Computação e Matemática Discreta pudessem ser divididas, visto que suas ementas contêm um volume extenso de tópicos e habilidades desejadas ao fim do semestre. Ao reduzir o volume de novos conhecimentos impostos aos alunos logo no primeiro semestre, talvez o aprendizado e fixação das ideias ocorreria de forma mais orgânica, motivando os alunos a permanecerem no curso em vez de abandoná-lo. É importante destacar que a própria introdução dos alunos a um curso superior causa outros impactos não discutidos no presente estudo, mas existentes e relevantes mesmo assim.

Uma maior conscientização por parte dos alunos deve existir que a construção do aprendizado em LC depende do embasamento lógico-matemático, assim como habilidades de solução de problemas que estão presentes ao longo do curso inteiro. Similarmente, os professores poderiam variar os métodos de ensino, uma vez que o volume de assuntos presentes nas ementas introdutórias podem aumentar a ansiedade dos alunos ingressantes, e assim interferir no seu aprendizado. Embora existam monitorias para o acompanhamento dos alunos menos experientes, esse recurso raramente é utilizado, visto que a maioria dos alunos de LC trabalha durante o dia e não têm tempo de frequentar as sessões.

\section{Conclusão}

A alta taxa de evasão no curso de LC na UFRPE pode ser explicada por vários motivos, como o fraco embasamento lógico-matemático e de programação dos alunos ingressantes, a organização da matriz curricular, e os métodos de ensino tradicionais. Tanto os professores como os alunos do curso percebem essas dificuldades, e uma grande parcela do alunado precisa repetir disciplinas introdutórias do curso, o que pode levar alguns deles a desistirem do curso. Embora a reestruturação da matriz curricular esteja sendo construída atualmente, uma reflexão mais profunda é necessária para assegurar a eficácia do ensino e aprendizado dos alunos.

O presente estudo identificou algumas percepções e observações do curso de LC na UFRPE por parte dos alunos e professores, e algumas sugestões de soluções foram 
apresentadas. Esse estudo indaga sobre o embasamento matemático-lógico dos alunos ingressantes no curso, assim como as metodologias de ensino empregadas nas disciplinas de Introdução à Computação, Matemática Discreta, e Algoritmos e Estruturas de Dados, e sugere uma possível reestruturação dos conteúdos, para diminuir a taxa de reprovação assim como a alta ocorrência da evasão do curso. Trabalhos futuros poderiam testar algumas dessas sugestões, ou até investigar os aspectos sociopedagógicos que podem influenciar na decisão de abandonar o curso. Outros trabalhos poderiam estender a pesquisa a cursos de LC em outras instituições ou até em outros tipos de Licenciatura. O bom preparo dos profissionais da educação é imprescindível para o futuro da humanidade, visto que professores são responsáveis pela formação de profissionais de todas as outras áreas. E visto que a Computação é uma área em constante transformação, cabe também aos formadores de futuros profissionais refletirem sobre o impacto de sua práxis na realidade e construção do conhecimento de seus alunos.

\section{Referências}

Ambrósio, A. P. et al. (2011). Programação de computadores: compreender as dificuldades de aprendizagem dos alunos.

dos Santos, R. P. and Costa, H. A. X. (2006). Análise de metodologias e ambientes de ensino para algoritmos, estruturas de dados e programação aos iniciantes em computação e informática. INFOCOMP, 5(1):41-50.

França, R. and Tedesco, P. (2015). Desafios e oportunidades ao ensino do pensamento computacional na educação básica no brasil. In Anais dos Workshops do Congresso Brasileiro de Informática na Educação, volume 4, page 1464.

Gomes, A., Henriques, J., and Mendes, A. (2008). Uma proposta para ajudar alunos com dificuldades na aprendizagem inicial de programação de computadores. Educação, Formação \& Tecnologias-ISSN 1646-933X, 1(1):93-103.

Júnior, J. and Rapkiewicz, C. E. (2004). O processo de ensino-aprendizagem de fundamentos de programação: uma visão crítica da pesquisa no brasil. In Anais do XII Workshop sobre Educação em Computação (SBC).

Prietch, S. S. and Pazeto, T. A. (2009). Análise, sugestões e perspectivas de um curso de licenciatura em informática. XVII WEI/CSBC, Bento Gonçalves/RS.

Prietch, S. S. and Pazeto, T. A. (2010). Estudo sobre a evasão em um curso de licenciatura em informática e considerações para melhorias. WEIBASE, Maceió/AL.

SILVA, I., Silva, I. M. M., and Santos, M. S. (2009). Análise de problemas e soluções aplicadas ao ensino de disciplinas introdutórias de programação. Universidade Federal Rural de Pernambuco, Recife-PE.

Thomas, J. W. (2000). A review of research on project-based learning. 